\title{
Outcomes of COVID-19 in the Eastern Mediterranean Region in the first 4 months of the pandemic
}

\author{
Ahmed S. BaHammam, MD, Khalid M. Bindayna, PhD, Ronni M. Joji, MD, \\ Haitham Jahrami, PhD, Mo'ez Al-Islam E. Faris, PhD, Nicola L. Bragazzi, PhD.
}

\begin{abstract}
الأهداف: تهدف هذه المراجعة الإطارية والتحليل التلوي إلى تلخيص إلخيص نتائج

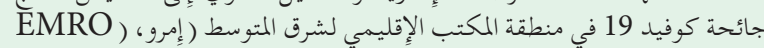
خلال الأشهر الأربعة الأولى من الجائحة .

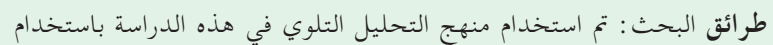

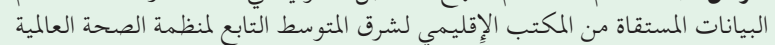

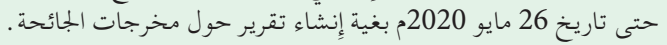

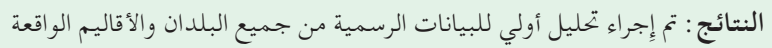

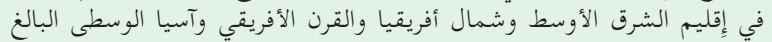

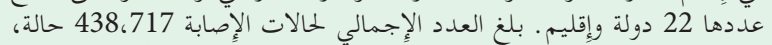
فيما بلغ عدد حالات التعافي

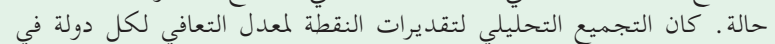

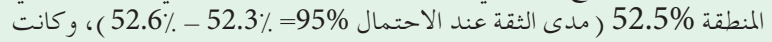

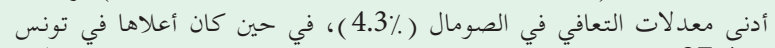

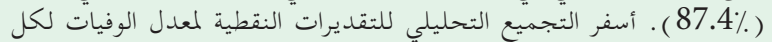

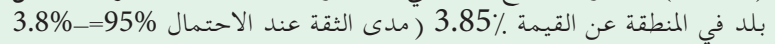

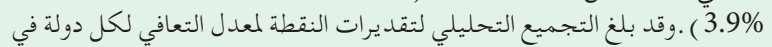

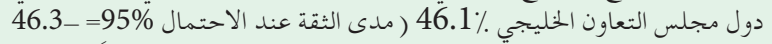

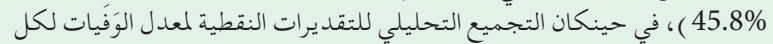

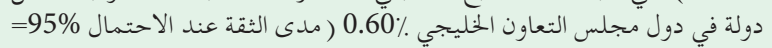
. (0.65\% - 0.50\%

الحلاصة : خلصت الدراسة إلىى وجود تباينات واسعة بين بلدان منطقة إِقليم الشرق

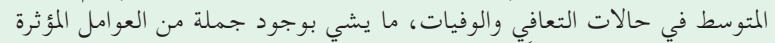

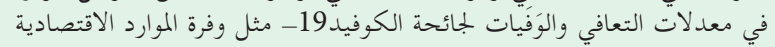

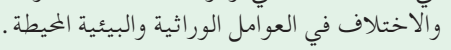

Objectives: To summarize the outcomes of the coronavirus disease 2019 infections in the Eastern Mediterranean Region (EMR) in the first 4 months of the pandemic.

Methods: A meta-analysis approach was used in this context. We used the aggregate data from the World Health Organization Regional Office for the EMRO (until 26 May 2020) to generate this report.

Results: An analysis of official data from all 22 countries and territories in the Middle East, North Africa, the Horn of Africa, and Central Asia $\mathrm{K}=22$ (a total of
438,717 cases) was performed. The total number of cases, recovered cases were 438,717,228,986, and deaths was 11,290 in the EMR. Meta-analytic pooling of the point estimates of recovery rate per country in the EMR was 52.5\% (95\% CI 52.3\% - 52.6\%). The lowest recovery rates were in Somalia (4.3\%), and the highest rates were in Tunisia (87.4\%). Meta-analytic pooling of the point estimates of death rate per country in the EMR yielded 3.85\% [95\% CI 3.80\% - 3.9\%]. Meta-analytic pooling of the point estimates of recovery rate per country in the Gulf Cooperation Council countries was 46.1\% (95\% CI 45.8\% - 46.3\%). Meta-analytic pooling of the point estimates of death rate per country in the Gulf Cooperation Council countries was 0.6\% (95\% CI $0.50 \%-0.65 \%)$.

Conclusion: Wide variability was found between EMR countries in recovery and mortality, implying the possible impact of resource availability, and genetic and environmental factors on the morality and recovery of the COVID-19.

Keywords: coronavirus disease, pandemic, recovery, mortality, SARS CoV-2.

Saudi Med J 2020; Vol. 41 (9): 907-915 doi: 10.15537/smj.2020.9.25320

From the Department of Medicine (BaHammam), College of Medicine, Respiratory Medicine, University Sleep Disorders Center, King Saud University; from The Strategic Technologies Program of the National Plan for Sciences and Technology and Innovation (BaHammam), Riyadh, Kingdom of Saudi Arabia; College of Medicine and Medical Sciences (Bindayna, Joji, Jahrami), Arabian Gulf University; from the Rehabilitation Services Department, Ministry of Health (Jahrami), Manama, Bahrain; from the Department of Clinical Nutrition and Dietetics (Faris), College of Health Sciences/Research Institute of Medical and Health Sciences, University of Sharjah, Sharjah, United Arab Emirates; and from the Department of Mathematics and Statistics, Laboratory for Industrial and Applied Mathematics (Bragazzi), York University, Toronto, Canada.

Received 28th May 2020. Accepted 9th August 2020

Address correspondence and reprint request to: Prof. Ahmed BaHammam, Director, Respiratory Medicine, University Sleep Disorders Center, College of Medicine, King Saud University, Riyadh, Kingdom of Saudi Arabia.E-mail:ashammam2@gmail.com

ORCID ID: https://orcid.org/0000-0002-1706-6167 
$\mathrm{C}$ oronaviruses are enveloped positive-sense singlestranded RNA viruses, which belong to the family Coronaviridae. They are divided into 4 types: alpha, beta, gamma, and delta coronaviruses. ${ }^{1,2}$ Alpha and beta-coronaviruses infect only mammals causing symptoms of respiratory infections in humans and gastroenteritis symptoms in other animals. ${ }^{3}$ Gamma and delta-coronaviruses infect birds generally, although some can cause infection in mammals. ${ }^{4}$ Over the past 7 decades, specialists have reported that coronaviruses can infect animals such as mice, rats, dogs, cats, turkeys, horses, pigs, and cattle. ${ }^{5}$ Betacoronaviruses are important as they comprise highly pathogenic viruses, including severe acute respiratory syndrome coronavirus (SARS-CoV), Middle East respiratory syndrome coronavirus (MERS-CoV), and severe acute respiratory syndrome coronavirus-2 (SARS-CoV-2). ${ }^{4}$

In late 2019, the first case of pneumonia was reported in Wuhan, the capital city of Hubei province in China. ${ }^{6}$ The pathogen was identified as SARS-CoV-2 (betacoronavirus), which is related to bat coronaviruses and SARS-CoV. ${ }^{6,7}$ Respiratory droplets were the mainform of spread during this pandemic. ${ }^{7}$ The assessed median incubation period is 5.1 days $(95 \%$ CI, 4.5 to 5.8 days), and the mean incubation period is 5.5 days. ${ }^{8}$ The period from the onset of symptoms to death is approximately 6 to 41 days. ${ }^{9}$ Asymptomatic carriers during the incubation period are a major source of infection. ${ }^{10}$ On 30 January 2020, the World Health Organization (WHO) has declared coronavirus disease 2019 (COVID-19), a Public Health Emergency of International Concern (PHEIC). On 11 March 2020, the WHO denoted COVID-19 as a pandemic. ${ }^{6}$

Clinical manifestations include fever, dry cough, dyspnea, myalgia, fatigue, lymphopenia, and pneumonia features on a chest radiograph, with ground glass (GGO) pattern is the most common finding in COVID-19 infections. Arrhythmia, renal injury, acute cardiac injury, acute respiratory distress syndrome (ARDS), and shock were among the most frequently

Disclosure. Authors have no conflict of interests, and the work was not supported or funded by any drug company. This work was supported by the Strategic Technologies Program of the National Plan for Sciences and Technology and Innovation in the Kingdom of Saudi Arabia (MED511-02-08). The study sponsors played no role in tailoring the study design, collection of data, analysis or interpretation of data, writing of the manuscript, nor decision to submit the manuscript. reported complications for COVID-19 infection. ${ }^{11}$

Owing to the widespread-ability and contagious nature of the COVID-19-causing coronavirus, it becomes crucial to building an international collaborative framework in the battle against the pandemic of this virus. Reporting incidence rates, mortality, and recovery rates for each specific region will help for a better understanding of the variable environmental and genetic factors involved in the development of the pandemic COVID-19 and will expand the knowledge and widen the understanding of the nature of that disease.

The pooled prevalence of mortality among patients with COVID-19 is an important variable to be determined to assess the impact of this pandemic. Hence, this work tried to systematically review and metaanalyze the available literature seeking to summarize the outcomes of the coronavirus disease 2019 infections in the Eastern Mediterranean Region (EMR). Health care providers, managers, and policymakers can use the findings to improve the performance of response to future pandemics.

The WHO Regional Office for the Eastern Mediterranean is one of the WHO's 6 regional offices around the world. It looks after the WHO EMR, which includes 21 states and Palestine (West Bank and Gaza Strip), with a total population of approximately 730 million people. Since the announcement of the first case of COVID-19 in the region, 438,717 have contracted the virus (until 26 May 2020).

The rationale to focus on EMR (region-specific outcomes) is that dependable and well-timed health information is crucial for policy development, good health management, decisions that are based on evidence-based, usage of resources and scrutinizing and appraisal of the public health situation. The expected importance of such a review is to gain insights on assessing health outcomes of COVID-19, specifically recovery and cause-specific mortality, and to assess health system reaction in the region.

Methods. We devised this scoping review exercising the proposed scoping review methodological framework ${ }^{12,13}$ and Tricco et $\mathrm{al}^{14}$ recent scoping review reporting guidelines.

Research questions. The scoping review was directed by the following question: "What are the outcomes (death or recovery) of COVID-19 in the EMR region?”

Data sources and searches. Eastern Mediterranean Region-based observational and interventional studies published between January 2020 and May 2020 related to COVID-19 outcomes were searched. 
The search strategy was developed using key topics in the review problem. For each key topic, appropriate keywords and Medical Subject Headings (MeSH) will be established. To assure the comprehensiveness and appropriateness of our searching on the electronic databases, specific text words will be abbreviated and used as full. The keywords and MeSH terms will be combined using Boolean logic operators: "AND" and "OR" appropriately. Obtained studies will be manually screened also for missed hits.

Two members of the review team independently performed the electronic search online in the following electronic databases: Cochrane, CINAHL, EMBASE, ScienceDirect, EBSCOhost, Scopus, Google Scholar, PubMed/MEDLINE, ProQuest Medical, and Web of Science databases.

To identify studies that reported the outcomes of COVID-19 in the EMR region. The following keywords and $\mathrm{MeSH}$ will be used: "Eastern Mediterranean" OR "Afghanistan" OR "Bahrain” OR "Djibouti” OR "Egypt" OR "Iran (the Islamic Republic of)" OR "Iraq" OR "Jordan" OR "Kuwait" OR "Lebanon" OR "Libya” OR "Morocco" OR "Oman" OR "Palestine (occupied Palestinian Territory)" OR "Pakistan" OR "Qatar" OR "Saudi Arabia (Kingdom of Saudi Arabia)" OR "Somalia" OR "Sudan" OR "Syrian Arab Republic" OR "Tunisia" OR "United Arab Emirates" OR "Yemen" AND "COVID-19" OR "Coronavirus disease 2019" OR "Severe Acute Respiratory Syndrome Coronavirus 2 (SARS-CoV-2)" OR "COVID19" or COVID-19" AND "outcomes" OR "outcome report" OR "situation report" OR "data" OR "recovery rate" OR "death rate" OR "mortality". The search will not be limited using any constrain.

Eligibility criteria. We were looking for studies that have used observational (cross-sectional, case-control, cohorts) and interventional (randomized controlled trials) epidemiological designs, involving COVID-19 patients in the EMR will be included.

Outcomes and measures. The anticipated outcome of this scoping review and meta-analysis is to report the outcomes ofCOVID-19 cases in the EMR after adjusting for moderates. The specific outcomes of interest will be to report: 1 ) the pooled death rate (all-cause mortality rate), which is defined by the number of total deaths relative to the cumulative number of confirmed human cases reported to the specified date; 2) the pooled number of recoveries (recovery rate), which is defined by the number of reported recoveries relative to the cumulative number of confirmed human cases reported to the specified date.
In this scoping review, we used grey literature in the form of the official report from local health authorities, and aggregate data from the WHO EMR made available online by 26 May 2020 (4 months after detecting the first COVID-19 in the region). ${ }^{15}$ Our report and metaanalysis, together with our study methodology, can be used in the future for conducting more rigorous metaanalyses.

Synthesis and analysis of data. Data were pooled using a fixed-effects model consistent with the Der Simonian-Laird method. The results report the pooled outcomes (recovery rate and death rate) and conform using 95\% confidence intervals (95\% CI). Besides, Forest plots were used to present data graphically. An assessment of countries' heterogeneity employing the $\mathrm{I}^{2}$ statistic was carried out; the value of 75 to $100 \%$ was used to signify high heterogeneity. Also, amongcountries, heterogeneity was evaluated in this review by the Cochran (Q) statistic test and tau-2 $\left(\tau^{2}\right)$. Covariate (or moderator) analyses were performed using meta-regression using the male to female gender ratio, median age, and the gross national income of each country to explain the heterogeneity. The scoping review wasexecuted via Comprehensive Meta-Analysis software, Version 3.0. ${ }^{16}$ Descriptive statisticswere achieved using STATA 16.1. ${ }^{17}$

No human subject participants will be directly involved. The approval from the research ethicscommittee is not required as we will only be analyzing secondary data.

Implications of the review. This report and metaanalysis aimed to summarize the outcomes of the corona virus disease 2019 infections in the EMR. Healthcare providers, managers, and policy makers can use the findings to improve the performance of response to future pandemics.

Results. Characteristics of included sources of this report. Twenty-two countries and regions in North Africa, Middle Eastthe Horn of Africa, and Central Asia $(\mathrm{K}=22)$, involving a total of 438,717 cases, contributed to the analyses (Table 1$).^{18}$

Sociodemographic data or clinical data of the cases were not available for analysis. This is because available data were aggregate available on WHO EMR.

The total number of cases in the EMR (as of 26 May 2020) was 438,71718 . The total number of recovered cases was 228,986 , while the total number of deaths was 11,29018 . Outcomes are measured in terms of recovery rates and death rates. ${ }^{18}$ 
COVID-19 in the EMRO region ... BaHammam et al

Table 1 - Summary of the outcomes of COVID-19 cases in the Eastern Mediterranean Region (EMR).

\begin{tabular}{|c|c|c|c|c|c|c|c|c|c|c|}
\hline Country & $\begin{array}{c}\text { Median } \\
\text { age* }^{*}\end{array}$ & $\begin{array}{l}\text { Male:female } \\
\text { ratio* }\end{array}$ & $\begin{array}{c}\text { Gross } \\
\text { national } \\
\text { income* }^{*}\end{array}$ & $\begin{array}{l}\text { Total } \\
\text { cases }\end{array}$ & $\begin{array}{l}\text { Total } \\
\text { deaths }\end{array}$ & $\begin{array}{l}\text { Total } \\
\text { recoveries }\end{array}$ & $\begin{array}{l}\text { Active } \\
\text { cases }\end{array}$ & $\begin{array}{l}\text { Serious } \\
\text { in ICU }\end{array}$ & Cases/1M & Deaths/1M \\
\hline Afghanistan & 18.4 & 105.4 & 1746 & 11831 & 220 & 1128 & 10483 & 19 & 305 & 6 \\
\hline Bahrain & 32.5 & 183.1 & 40399 & 9171 & 14 & 4753 & 4404 & 8 & 5411 & 8 \\
\hline Djibouti & 26.6 & 110.7 & 3601 & 2468 & 14 & 1079 & 1375 & NA & 2502 & 14 \\
\hline Egypt & 24.6 & 102.1 & 10744 & 17967 & 783 & 4900 & 12284 & 41 & 176 & 8 \\
\hline Iran & 32.0 & 102.0 & 18166 & 137724 & 7451 & 107713 & 22560 & 2585 & 1642 & 89 \\
\hline Iraq & 21.0 & 102.5 & 15365 & 4632 & 163 & 2811 & 1658 & NA & 115 & 4 \\
\hline Jordan & 30.7 & 94.3 & 8268 & 711 & 9 & 479 & 223 & 5 & 70 & 0.9 \\
\hline Kuwait & 36.8 & 157.9 & 71164 & 21967 & 165 & 6621 & 15181 & 182 & 5152 & 39 \\
\hline Lebanon & 29.6 & 101.4 & 11136 & 1119 & 26 & 688 & 405 & 4 & 164 & 4 \\
\hline Libya & 19.4 & 101.1 & 11685 & 75 & 3 & 40 & 32 & $\mathrm{NA}$ & 11 & 0.4 \\
\hline Morocco & 29.5 & 98.5 & 7480 & 7532 & 200 & 4774 & 2558 & 1 & 204 & 5 \\
\hline Oman & 30.6 & 194.1 & 37039 & 7770 & 37 & 1933 & 5800 & 31 & 1526 & 7 \\
\hline Pakistan & 22.8 & 106.0 & 5190 & 57705 & 1197 & 18314 & 38194 & 111 & 262 & 5 \\
\hline Palestine & 20.8 & 102.9 & 5314 & 423 & 3 & 357 & 63 & $\mathrm{NA}$ & 83 & 0.6 \\
\hline Qatar & 32.3 & 302.4 & 110489 & 45465 & 26 & 10363 & 35076 & 202 & 15809 & 9 \\
\hline Saudi Arabia & 31.8 & 137.1 & 49338 & 74795 & 399 & 45668 & 28728 & 384 & 2152 & 11 \\
\hline Somalia & 18.5 & 103.0 & $\mathrm{NA}$ & 1689 & 66 & 235 & 1388 & 2 & 107 & 4 \\
\hline Sudan & 19.7 & 99.8 & 3962 & 3976 & 170 & 503 & 3303 & NA & 91 & 4 \\
\hline Syria & 25.6 & 100.2 & 2725 & 106 & 4 & 41 & 61 & NA & 6 & 0.2 \\
\hline Tunisia & 31.6 & 97.5 & 10677 & 1051 & 48 & 919 & 84 & 3 & 89 & 4 \\
\hline $\begin{array}{l}\text { United Arab } \\
\text { Emirates }\end{array}$ & 32.6 & 223.9 & 66912 & 30307 & 248 & 15657 & 14402 & 1 & 3068 & 25 \\
\hline Yemen & 20.2 & 101.5 & 1433 & 233 & 44 & 10 & 179 & NA & 8 & 1 \\
\hline Total & & & & 438,717 & 11,290 & 228,986 & 198,441 & 3,579 & - & - \\
\hline \multicolumn{11}{|c|}{$\begin{array}{c}\text { *country-level data, N/A: not available } \\
\text { Data Source: WHO/EMRO } 26 \text { May 2020 }\end{array}$} \\
\hline
\end{tabular}

Recovery rate. The pooling of the point estimates of recovery rate per country in the EMR was $52.5 \%$ (95\% CI 52.3\% - 52.6\%), with statistical significance present between-countries heterogeneity $(\mathrm{Q}=77912.9$, $\left.\tau^{2}=1.1, \mathrm{I}^{2}=99.9 \%, p<0.001\right)$. A visual examination of the plot showed no bias. The Duval and Tweedie's procedure indicated that if the point estimate was to be adjusted for bias right or left of the mean; it would persist unchanged for the fixed effects model. The lowest recovery rates were in Yemen $(4.3 \%)$, and the highest recovery rates were in Tunisia $(87.4 \%)$. There is a significant heterogeneity (Figure 1 ). Median age $(\beta=0.1, p=0.001)$, male to female gender ratio $(\beta=-0.01$, $p=0.001)$, and gross national income $(\beta=-0.001$, $p=0.001)$ were all significant predictors of recovery rate.

Death rate. Meta-analytic pooling of the point estimates of death rate per country in the EMR was $3.85 \%$ (95\% CI 3.80\% - 3.90\%), with statistical significance present between-countries heterogeneity $\left(\mathrm{Q}=5185, \tau^{2}=0.87, \mathrm{I}^{2}=99.6 \%, p<0.001\right)$. A visual inspection of the plot indicated no bias. The Duval and Tweedie's procedure indicated that if the point 
estimate was to be adjusted for bias left or right of the mean, it would remain unchanged for the fixed effects model. The lowest recovery rates were in Qatar $(0.1 \%)$, and the highest recovery rates were in Yemen $(18.9 \%)$. There is a significant heterogeneity (Figure 2). Median age $(\beta=0.03, p=0.001)$, male to female gender ratio $(\beta=-0.02, p=0.001)$, and gross national income $(\beta=-0.001, p=0.001)$ were all significant predictors of recovery rate.

Outcomes in the Gulf Cooperation Council (GCC) countries. In a subgroup analysis, we analyzed data in the GCC countries. The pooling of the point
Study name

$\begin{array}{lccccc} & \text { Event } & \text { Lower } & \text { Upper } & & \\ & \text { rate } & \text { limit } & \text { limit } & \text { Z-Value } & \text { p-Value } \\ \text { Afghanistan } & 0.019 & 0.016 & 0.021 & -58.277 & 0.000 \\ \text { Bahrain } & 0.002 & 0.001 & 0.003 & -24.239 & 0.000 \\ \text { Djibouti } & 0.006 & 0.003 & 0.010 & -19.276 & 0.000 \\ \text { Egypt } & 0.044 & 0.041 & 0.047 & -84.521 & 0.000 \\ \text { Iran (Islamic Republic of) } & 0.054 & 0.053 & 0.055 & -240.210 & 0.000 \\ \text { Iraq } & 0.035 & 0.030 & 0.041 & -41.524 & 0.000 \\ \text { Jordan } & 0.013 & 0.007 & 0.024 & -12.987 & 0.000 \\ \text { Kuwait } & 0.008 & 0.006 & 0.009 & -62.498 & 0.000 \\ \text { Lebanon } & 0.023 & 0.016 & 0.034 & -18.840 & 0.000 \\ \text { Libya } & 0.040 & 0.013 & 0.117 & -5.393 & 0.000 \\ \text { Morocco } & 0.027 & 0.023 & 0.030 & -50.255 & 0.000 \\ \text { Oman } & 0.005 & 0.003 & 0.007 & -32.419 & 0.000 \\ \text { Pakistan } & 0.021 & 0.020 & 0.022 & -131.969 & 0.000 \\ \text { Occupied Palestinian territory, including } & 0.025 & -8.529 & 0.000 \\ \text { Qatar } & 0.002 & 0.022 & -3.059 & 0.000 \\ \text { Saudi Arabia } & 0.001 & 0.000 & 0.001 & -38.059 \\ \text { Somalia } & 0.005 & 0.005 & 0.006 & -104.154 & 0.000 \\ \text { Sudan } & 0.039 & 0.031 & 0.049 & -25.503 & 0.000 \\ \text { Syrian Arab Republic } & 0.043 & 0.037 & 0.050 & -39.654 & 0.000 \\ \text { Tunisia } & 0.038 & 0.014 & 0.096 & -6.354 & 0.000 \\ \text { United Arab Emirates } & 0.046 & 0.035 & 0.060 & -20.572 & 0.000 \\ \text { Yemen } & 0.008 & 0.007 & 0.009 & -75.241 & 0.000 \\ & 0.189 & 0.144 & 0.244 & -8.708 & 0.000 \\ & 0.038 & 0.038 & 0.039 & -334.638 & 0.000\end{array}$

Event rate and $95 \% \mathrm{Cl}$

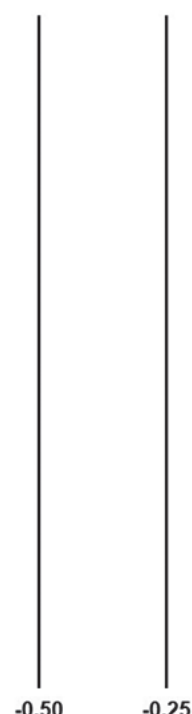

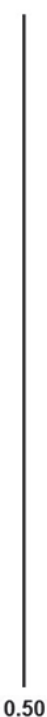

Figure 1 - The recovery rate of COVID-19 cases in the Eastern Mediterranean Region (EMR).

\section{Study name}

Afghanistan

Bahrain

Djibouti

Egypt

Iran (Islamic Republic of)

Iraq

Jordan

Kuwait

Lebanon

Libya

Morocco

Oman

Pakistan

occupied Palestinian territory, including east Jerusale

Qatar

Saudi Arabia

Somalia

Sudan

Syrian Arab Republic

Tunisia

United Arab Emirates

Yemen
Statistics for each study

$\begin{array}{cccrr}\begin{array}{c}\text { Event } \\ \text { rate }\end{array} & \begin{array}{c}\text { Lower } \\ \text { limit }\end{array} & \begin{array}{l}\text { Upper } \\ \text { limit }\end{array} & \text { Z-Value } & \text { p-Value } \\ 0.019 & 0.016 & 0.021 & -58.277 & 0.000 \\ 0.002 & 0.001 & 0.003 & -24.239 & 0.000 \\ 0.006 & 0.003 & 0.010 & -19.276 & 0.000 \\ 0.044 & 0.041 & 0.047 & -84.521 & 0.000 \\ 0.054 & 0.053 & 0.055 & -240.210 & 0.000 \\ 0.035 & 0.030 & 0.041 & -41.524 & 0.000 \\ 0.013 & 0.007 & 0.024 & -12.987 & 0.000 \\ 0.008 & 0.006 & 0.009 & -62.498 & 0.000 \\ 0.023 & 0.016 & 0.034 & -18.840 & 0.000 \\ 0.040 & 0.013 & 0.117 & -5.393 & 0.000 \\ 0.027 & 0.023 & 0.030 & -50.255 & 0.000 \\ 0.005 & 0.003 & 0.007 & -32.419 & 0.000 \\ 0.021 & 0.020 & 0.022 & -131.969 & 0.000 \\ 0.007 & 0.002 & 0.022 & -8.529 & 0.000 \\ 0.001 & 0.000 & 0.001 & -38.059 & 0.000 \\ 0.005 & 0.005 & 0.006 & -104.154 & 0.000 \\ 0.039 & 0.031 & 0.049 & -25.503 & 0.000 \\ 0.043 & 0.037 & 0.050 & -39.654 & 0.000 \\ 0.038 & 0.014 & 0.096 & -6.354 & 0.000 \\ 0.046 & 0.035 & 0.060 & -20.572 & 0.000 \\ 0.008 & 0.007 & 0.009 & -75.241 & 0.000 \\ 0.189 & 0.144 & 0.244 & -8.708 & 0.000 \\ 0.038 & 0.038 & 0.039 & -334.638 & 0.000\end{array}$

Event rate and $95 \% \mathrm{Cl}$

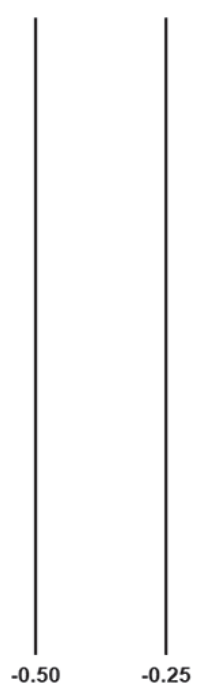

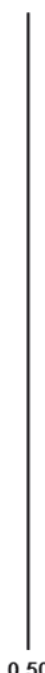

Figure 2 - The death rate of COVID-19 cases in the Eastern Mediterranean Region (EMR). 
estimates of recovery rate per country in the GCC was $46.1 \%$ (95\% CI 45.8\% - 46.3\%), with statistically significant evidence of between-countries heterogeneity $\left(\mathrm{Q}=19554, \tau^{2}=0.64, \mathrm{I}^{2}=99.9 \%, p<0.001\right)$.

Meta-analytic pooling of the point estimates of death rate per country in the GCC was $0.60 \%$ (95\% CI $0.50 \%-0.65 \%$ ), with statistically significant evidence of between-countries heterogeneity $\left(\mathrm{Q}=209.9, \tau^{2}=0.34\right.$, $\left.I^{2}=97.60 \%, p<0.001\right)$.

Discussion. Because time is crucial in COVID-19 activities, this meta-analysis of available data was performed to examine the outcome of COVID-19 in the EMR. All countries, particularly developing countries, have constraints and a limited budget and resources in tackling the consequences of pandemics, as is currently happening with COVID-19. ${ }^{19}$ Developing countries do not have all the necessary basic levels of health infrastructure to deal with day-to-day health emergencies and threats of this pandemic. ${ }^{20}$ COVID-19 is a new viral infection, and our knowledge of patient outcomes and the factors affecting them is still evolving. COVID-19 surveillance and studies conducted in individual setup are not generalizable. In order to get a complete in-depth picture of the patient outcomes and to study the trend of these outcomes over time, there is a mass need for conducting scoping review and metaanalysis.

In anticipation of the rise over the coming weeks, it is important to predict what is the mortality of this infection in this region to expedite research and prepare access to the treatment and prevention facilities of COVID-19. Therefore, a summary of the outcomes of the COVID-19 infections in the EMR is necessary at this stage to allow health care providers, managers, and policy makers to use the available findings to improve the performance of response to the current and future pandemics. This meta-analysis provides timelyneeded information about mortality and recovery of COVID-19 cases and its relation to demographics and socioeconomic status to the health policy makers and planners in the region using the PRISMA statement to achieve as high a level of quality as possible in reporting and methodology. ${ }^{21}$

The Chinese Center for Disease Control and Prevention reported that most SARS-CoV-2 infections produce mild disease, and the case fatality rate was $2.9 \%$ in Hubei province compared to $0.4 \%$ (other Chinese provinces). ${ }^{22}$ As of 26 May 2020, 215 countries or territories are affected, with a total of 5,622,828 documented cases of COVID-19 and 348,710 deaths globally. ${ }^{23}$ In the current report, there was variability between EMR countries in recovery and mortality rates. Mortality rate in the GCC countries was $0.6 \%$ (95\% CI $0.55 \%-0.65 \%$ ), which is lower than that reported in whole EMR countries, 3.8\% (95\% CI 3.80\% - 3.90\%). Variable mortality rates have been reported in different countries, with a case fatality ratio ranging from $18.9 \%$ to $0.1 \% .{ }^{24}$ Recovery rate, on the other hand, in the GCC countries was 46.1\% (95\% CI 45.8\% - 46.3\%), which is lower than that reported in whole EMR region countries, $52.5 \%$ (95\% CI 52.3\% - 52.6\%).

According to the Worldometer Coronavirus, the absolute number of cases in Asia as a whole is 999,653 , with reports a recovery rate of $58.5 \% .^{25}$ This is comparative to the pooled recovery rate from our analysis for the EMR. Of all the regions, the North American region has the second most number of cases $1,908,368$ and also reported the least recovery rate of $30.40 \% .{ }^{26}$ This is followed by Europe with 1,932,118 cases and a recovery rate of $47 \%$, South American region with 656,612 cases with a recovery rate of $40.2 \%$, African region with 118,615 cases, and a recovery rate of $40.6 \% .^{26}$ Oceania has the least number of cases and the best recovery rate of all regions. The absolute number of cases in Oceania is 8,741, with a recovery rate of $92.8 \% .^{26}$

During the exponential rise stage of an epidemic, the documented time lags between the beginning of symptoms and outcome (death), ${ }^{27}$ therefore, dividing the aggregate reported the number of deaths by the aggregate number of reported cases would probably underrate the exact case fatality ratio in the early stages of an epidemic; a matter that is important to realize when reporting the final clinical outcome. Additionally, scrutiny of a newly appeared pathogen is usually biased in the direction of discovering clinically severe cases, particularly at the beginning of an epidemic when the diagnostic capability is low. ${ }^{27}$ It is likely that some countries apply less screening, and hence only diagnose sick cases that seek medical advice. On the other hand, some countries are more proactive in implementing active surveillance, which enables them to detect mild or even asymptomatic cases. ${ }^{28}$ Therefore, approximations of the case-fatality ratio can be shifted up until the degree of clinically milder disease is verified. ${ }^{29}$

For example, initial data from the site of the outbreak (Wuhan) had chiefly been obtained through hospital surveillance representing patients with moderate or severe illness. Hence, it is likely to provide higher estimates of fatality. ${ }^{30}$ On the other hand, subsequent data from mainland China, where alert to the risk of infection has improved, resulting in active surveillance of travelers and those with a broader set of clinical 
criteria for defining a suspected case, resulted in the detection of clinically mild cases and lower fatality rates. ${ }^{27}$ Additionally, in this report, we lack data on demographics, which may impact both mortality and recovery. Older populations, males, and obese subjects were of higher mortality rates than others. ${ }^{27,31}$ Moreover, comorbidities have been shown to increase the mortality of COVID-19. ${ }^{32}$

We found substantial inter-country variability in our study. The recovery rate ranged between $4.3 \%$ to $87.4 \%$. Similar trends were observed in other regions of the world. This result highlights that multiple factors might influence patient outcomes. While all the countries are striving to control COVID-19 and are trying to provide care to their citizens, some are witnessing better results than others. Through learning and adopting the best practices from each other, it is possible to optimize the resources used and to increase the favorable outcomes of COVID-19 cases.

The variability of recovery rates could be related to the definitions used to define recovery. Both medical and testing criteria must be met before a person is declared recovered. The Centers for Disease Control and Prevention(CDC) stated that: "The decision to discontinue isolation should be undertaken in the context of local conditions and case progressions. Current options include both i) a time-since-illnessonset and time-since-recovery (non-test-based) strategy, and ii) test-based strategy". ${ }^{33}$ Therefore, patients have to be fever-free (without fever-reducing medications) for a minimum of 3 consecutive days. Additionally, they need to show an improvement in respiratory and other symptoms for at least 7 full days since the symptoms began. In addition to the above clinical criteria, the CDC criteria mandate 2 negative tests (of an FDA Emergency Use Authorized molecular assay for COVID-19) for SARS-CoV-2 that were taken at least 24 hours apart. Studies have reported prolonged viral shedding with high sputum viral load after recovery. ${ }^{34-36}$ Moreover, genetic factors cannot be ruled out. Therefore, future studies should assess the link between genetics and mortality and recovery of COVID-19.

A recent CDC MMWR report indicated an over representation of blacks among hospitalized patients with COVID-19. ${ }^{23}$ With regards to deaths among COVID-19 patients, race and ethnicity seem to have a role. Data from New York City identified death rates among Black Americans to be 92.3 deaths/100,000 population and among Hispanic Americans 74.3 deaths/100,000, which were significantly higher than that of white Americans 45.2 deaths/100,000 or Asians
34.5 deaths $/ 100,000 .{ }^{26}$ In addition to a possible role of genetics, these differences among ethnic and racial groups could also be related to economic and social conditions. ${ }^{37}$ In public health emergencies, such as the COVID-19 pandemic, these conditions can limit the access of certain groups to the needed resources to prepare for and respond to emergencies. ${ }^{38}$ Additionally, living in heavily inhabited regions may make it difficult to apply prevention measures like social distancing. Moreover, economic status in different countries may influence the outcomes. Workers with unpaid sick leave are more prone to continue to work even when they are sick; therefore, presenting late to the healthcare services. ${ }^{39}$

Study limitations. Due to the limited availability of data, we have not considered the demographic factors of the COVID-19 patients and the type of care and treatment received by the patients. Several risk factors, including age and comorbidities, are known to affect patient outcomes. Consideration of these might have given a comprehensive understanding.

Additionally, information about this pandemic in different countries of the world changes by the day/ week. As such, we have to be very careful making interpretations, and always take outcomes with caution in conclusion and recommendations.

In conclusions, this timely scoping review and metaanalysis examined mortality and recovery in the EMR region. We have presented a framework to systematically analyze patient outcomes of COVID-19. The current report showed a vast inter-country variation in both the recovery rates and death rates.

This is a preliminary report of our meta-analysis protocol, once more original studies are completed, an updated version of this scoping review will provide an additional resource of COVID-19 behavior and outcome in the EMR region, which will help health planners to anticipate the management steps needed to control future pandemics.

\section{References}

1. Biswas A, Bhattacharjee U, Chakrabarti AK, Tewari DN, Banu H, Dutta S. Emergence of Novel Coronavirus and COVID-19: whether to stay or die out? Crit Rev Microbiol 2020: 1-12.

2. Gorbalenya AE, Baker SC, Baric RS, de Groot RJ, Drosten C, Gulyaeva AA, et al. The species severe acute respiratory syndrome-related coronavirus: classifying 2019-nCoV and naming it SARS-CoV-2. Nature Microbiology 2020; 5: 536-544.

3. Rabi FA, Al Zoubi MS, Kasasbeh GA, Salameh DM, Al-Nasser AD. SARS-CoV-2 and Coronavirus Disease 2019: What We Know So Far. Pathogens 2020; 9: (3). 
4. Khan S, Siddique R, Shereen MA, Ali A, Liu J, Bai Q, et al. Emergence of a Novel Coronavirus, Severe Acute Respiratory Syndrome Coronavirus 2: Biology and Therapeutic Options. J Clin Microbiol 2020; 58: (5).

5. Syed A. Coronavirus: A mini review. Int J Curr Res Med Sci 2020; 6: 8-10.

6. Guan WJ, Ni ZY, Hu Y, Liang WH, Ou CQ, He JX, et al. Clinical Characteristics of Coronavirus Disease 2019 in China. N Engl J Med 2020; 382:1708-1720.

7. Gandhi RT, Lynch JB, Del Rio C. Mild or Moderate Covid-19. N Engl J Med 2020; 10.1056

8. Lauer SA, Grantz KH, Bi Q, Jones FK, Zheng Q, Meredith $\mathrm{HR}$, et al. The incubation period of coronavirus disease 2019 (COVID-19) from publicly reported confirmed cases: Estimation and application. Ann Intern Med 2020; 172: 577-582.

9. Rothan HA, Byrareddy SN. The epidemiology and pathogenesis of coronavirus disease (COVID-19) outbreak. J Autoimmun 2020; 109: 102433.

10. Ye F, Xu S, Rong Z, Xu R, Liu X, Deng P, et al. Delivery of infection from asymptomatic carriers of COVID-19 in a familial cluster. Int J Infect Dis 2020; 94: 133-138.

11. Lei S, Jiang F, Su W, Chen C, Chen J, Mei W, et al. Clinical characteristics and outcomes of patients undergoing surgeries during the incubation period of COVID-19 infection. EClinicalMedicine 2020; 21: 100331.

12. Munn Z, Peters MDJ, Stern C, Tufanaru C, McArthur A, Aromataris E. Systematic review or scoping review? Guidance for authors when choosing between a systematic or scoping review approach. BMC Med Res Methodol 2018; 18: 143.

13. Arksey H, O’Malley L. Scoping studies: towards a methodological framework. Int J Soc Res Methodol 2005; 8: 19-23.

14. Tricco AC, Lillie E, Zarin W, O’Brien K, Colquhoun H, Kastner $\mathrm{M}$, et al. A scoping review on the conduct and reporting of scoping reviews. BMC Med Res Methodol 2016; 16: 15.

15. World Health Organization. Eastern Mediterranean region COVID-19 affected countries. [cited 2020 April 29]. Available from: https://covid19.who.int/

16. Borenstein M, Hedges LV, Higgins J, Rothstein HR. Comprehensive Meta-Analysis (Version 3). Englewood (NJ): Biostat; 2014.

17. Stata MPtE. 16.0. College Station, TX: StataCorp. 2019. Available from URL: www.stata.com

18. World Health Organization. WHO Coronavirus Disease (COVID-19) Dashboard: Word Health Organization. [cited 2020 May 3]. Available from: https://covid19.who.int/

19. BoswerAD. Real-worldshortagesnotaddressedinnewCOVID-19 Guidance. [cited 2020; Accessed 2020 May 6]. Available from: https://www.medscape.com/viewarticle/927209 p.].

20. Davies SE, Kamradt-Scott A, Rushton S. Disease diplomacy: international norms and global health security. International Affairs 2015; 91: 1178-1180.

21. Liberati A, Altman DG, Tetzlaff J, Mulrow C, Gøtzsche PC, Ioannidis JPA, et al. The PRISMA Statement for Reporting Systematic Reviews and Meta-Analyses of Studies That Evaluate Health Care Interventions: Explanation and Elaboration. PLOS Medicine 2009; 6: e1000100.
22. Bedford J, Enria D, Giesecke J, Heymann DL, Ihekweazu C, Kobinger G, et al. COVID-19: towards controlling of a pandemic. Lancet 2020; 395: 1015-1018.

23. Garg S, Kim L, Whitaker M, O'Halloran A, Cummings C, Holstein R, et al. Hospitalization Rates and Characteristics of Patients Hospitalized with Laboratory-Confirmed Coronavirus Disease 2019 - COVID-NET, 14 States, March 1-30, 2020. MMWR Morb Mortal Wkly Rep 2020; 69: 458-464.

24. Johns Hopkins University \& Medicine. Mortality Analyses. [updated 2020; accessed 2020 May 2]. Available from: https://coronavirus.jhu.edu/data/mortality

25. Wei WE, Li Z, Chiew CJ, Yong SE, Toh MP, Lee VJ. Presymptomatic Transmission of SARS-CoV-2 - Singapore, January 23-March 16, 2020. MMWR Morb Mortal Wkly Rep 2020; 69: 411-415.

26. NYC Health. Age-adjusted rates of lab confirmed COVID-19 non-hospitalized cases, estimated non-fatal hospitalized cases, and patients known to have died 100,000 by race/ethnicity group as of April 16, 2020. [Updated 2020; Accessed 2020 May 15]. Available from: https:/www1.nyc.gov/assets/doh/downloads/ pdf/imm/covid-19-deaths-race-ethnicity-04162020-1.pdf

27. Verity R, Okell LC, Dorigatti I, Winskill P, Whittaker C, Imai N, et al. Estimates of the severity of coronavirus disease 2019: a model-based analysis. Lancet 2020: 20: 669-677.

28. Ministry of Health. Ministry of Health continues with active surveillance, COVID-19 monitoring committee stresses. [Updated 2020; Accessed 2020 May 2]. Available from: https:// www.moh.gov.sa/en/Ministry/MediaCenter/News/Pages/ News-2020-04-18-003.aspx.

29. Garske T, Legrand J, Donnelly CA, Ward H, Cauchemez S, Fraser C, et al. Assessing the severity of the novel influenza A/ H1N1 pandemic. BMJ 2009; 339: b2840.

30. Epidemiology Working Group for NCIP Epidemic Response, Chinese Center for Disease Control and Prevention. [The epidemiological characteristics of an outbreak of 2019 novel coronavirus diseases (COVID-19) in China]. Zhonghua Liu Xing Bing Xue Za Zhi 2020; 41: 145-151. Chinese.

31. Dietz W, Santos-Burgoa C. Obesity and its Implications for COVID-19 Mortality. Obesity (Silver Spring) 2020; 28: 1005.

32. Guan WJ, Liang WH, Zhao Y, Liang HR, Chen ZS, Li YM, et al. Comorbidity and its impact on 1590 patients with Covid-19 in China: A Nationwide Analysis. Eur Respir J 2020; 55 : 2001227.

33. Centers for Disease Control and Prevention. Discontinuation of Isolation for Persons with COVID-19 Not in Healthcare Settings (Interim Guidance) USA: Centers for Disease Control and Prevention. [Updated 2020; Accessed 2020 May 2]. Available from: https:/www.cdc.gov/coronavirus/2019-ncov/ hcp/disposition-in-home-patients.html.

34. Young BE, Ong SWX, Kalimuddin S, Low JG, Tan SY, Loh J, et al. Epidemiologic Features and Clinical Course of Patients Infected With SARS-CoV-2 in Singapore. JAMA 2020; 323: 1488-1494.

35. Rothe C, Schunk M, Sothmann P, Bretzel G, Froeschl G, Wallrauch C, et al. Transmission of 2019-nCoV infection from an Asymptomatic Contact in Germany. N Engl J Med 2020; 382: $970-971$. 
36. Cai J, Xu J, Lin D, Yang Z, Xu L, Qu Z, et al. A Case Series of children with 2019 novel coronavirus infection: clinical and epidemiological features. Clin Infect Dis 2020: ciaa198. doi: $10.1093 / \mathrm{cid} / \mathrm{ciaa} 198$.

37. Centers for Disease Control and Prevention. COVID-19 in Racial and Ethnic Minority Groups: Centers for Disease Control and Prevention. [Updated 2020; Accessed 2020 May 4]. Available from: https://www.cdc.gov/coronavirus/2019ncov/need-extra-precautions/racial-ethnic-minorities.html.
38. Bolin B, Kurtz LC. Race, Class, Ethnicity, and Disaster Vulnerability. In: Rodríguez H, Donner W, Trainor J, editors. Handbook of Disaster Research Handbooks of Sociology and Social Research. Cham: Springer; 2018. p. 10.1007/978-3-31963254-4_10.

39. US Bureau of Labor Statistics R. Labor force characteristics by race and ethnicity, 2018: US Bureau of Labor Statistics; 2019 [Updated 2019; Accessed 2020 May 5]. Available from: https:// www.bls.gov/opub/reports/race-and-ethnicity/2018/home.htm

\section{Illustrations, Figures, Photographs}

All figures or photographs should be submitted in a high resolution (minimum 300 DPI) electronic version saved in jpeg or tiff format. Original hard copies of all figures may be requested when necessary. Photographs will be accepted at the discretion of the Editorial Board. All lettering, arrows, or other artwork must be done by an artist or draftsman. If arrows are used please ensure they appear in a different color to the background color, preferably black with a white border, or white with a black border. If arrows distinguish different items on the figure then different arrow styles should be used ie. long, short, wide, narrow. Written informed consent for publication must accompany any photograph in which the subject can be identified. Written copyright permission, from the publishers, must accompany any illustration that has been previously published. 